\title{
Conformational and constitutional analysis of dental caries following radiotherapy for head and neck cancer
}

\author{
Joslei Carlos Bohn¹, Cassiano Lima Chaiben², Suzana Soares de Souza ${ }^{3}$, \\ Anelize Manuela Bahniuk Rumbelsperger ${ }^{4}$, Ângela Fernandes ${ }^{1}$, Maria Ângela Naval Machado ${ }^{1}$, \\ Thiago Gomes da Silva ${ }^{4}$, Antonio Adilson Soares de Lima ${ }^{1}$ \\ ${ }^{1}$ Department of Stomatology, School of Dentistry, Universidade Federal do Paraná - UFPR, Curitiba, Brazil \\ ${ }^{2}$ School of Health Sciences, Pontifícia Universidade Católica do Paraná - PUCPR, Curitiba, Brazil \\ ${ }^{3}$ Liga Norte Riogrande contra o Câncer - Hospital Luiz Antonio, Natal, Brazil \\ ${ }^{4}$ Department of Geology, Universidade Federal do Paraná - UFPR, Curitiba, Brazil
}

\begin{abstract}
Background: This study aimed to investigate the morphology and chemical composition of dental caries related to ionizing radiation (DCIR), an aggressive and progressive disease that affects dental hard tissues.

Materials and methods: Eight human teeth with DCIR were paired with sixteen control teeth (8 teeth with conventional caries and 8 without caries) and included in this study. An analysis of the morphology of the lesions was performed using the following techniques: periapical radiography, cone beam computed tomography, computed microtomography, and scanning electron microscopy. The chemical composition was assessed using X-ray dispersive spectroscopy.

Results: There was more demineralization in DCIR lesions when compared to conventional dental caries, even though there was no cavitation in the cervical region of the teeth. The superficial roughness and topography of DCIR lesions were similar to those of healthy teeth. On the other hand, lesions of conventional dental caries showed greater surface and topographic irregularity when compared to DCIR and healthy teeth $(p=0.001)$. Calcium $(C a)$ and phosphorus $(P)$ levels were lower in DCIR lesions when compared to controls. However, higher levels of carbon $(C)$ have been observed in DCIR lesions. There was a greater loss of the mineral matrix in DCIR followed by conventional caries. The reduction in the mineral matrix (Ca and P) was compatible with the imaging patterns observed in teeth with DCIR and conventional caries.

Conclusion: Despite their rapid evolution, DCIR presents an irregular, apparently intact surface with significant changes in the amount of $\mathrm{Ca}, \mathrm{P}$, and $\mathrm{C}$.

Key words: dental caries; radiotherapy; computed tomography; computed microtomography; electron microscopy; spectroscopy

Rep Pract Oncol Radiother 2021;26(3):389-399
\end{abstract}

\section{Introduction}

Radiotherapy is a treatment for head and neck cancer that uses ionizing radiation to destroy neoplastic cells [1]. However; it is not a selective treat- ment modality. Then, patients with cancer in the head and neck region treated by radiotherapy may present different sequelae [2-5]. When underestimated, these complications can negatively affect patients' quality of life [6]. 
The exacerbated advance of demineralization of dental structures (especially dentin) and salivary changes contribute to the appearance of carious lesions. Dental caries related to ionizing radiation (DCIR) is a highly destructive and progressive form of tooth decay $[7,8]$. Its incidence is $29 \%$ in the population and may increase when no preventive measure is instituted [9]. In general, it begins in the cervical region of the buccal surface of the teeth and can extend to mesial and distal surfaces. In many patients, the initial lesions of DCIR exhibit a smooth diffused brown surface in the cervical region of the teeth $[10,11]$. DCIR increases the fragility of the tooth structure that can culminate in a fracture of the dental crown $[7,10,12,13]$. Clinically, changes in the degree of demineralization and the color of the enamel affected by DCIR can confuse the dentist [14].

Conventional caries exhibit significantly decreased levels of calcium and phosphorus in regions where there was demineralized dentin when compared to healthy teeth $[15,16]$. Teeth with DCIR exhibit a loss of mineralized matrix in the area of the dentin-enamel junction (DEJ) and cementum. Some authors believe that there is a "delamination" of the enamel near the JAD, even on the healthy dental surface [10]. The analysis of teeth with DCIR by computed microtomography revealed that there is an extensive radiographic pattern of demineralization in the cervical region of the teeth. These changes can be observed even in decayed teeth with the enamel surface stained and still without cavitation. These findings reinforce the hypothesis that DCIR injuries are more destructive than they appear to be [11].

The pathogenesis of DCIR is still uncertain and the subject of much discussion in the literature [13, $17,18]$. Despite this, it is believed that the radiation used by radiotherapy can have direct effects on the tooth. This fact leads to changes in the microscopic morphology of the enamel and dentin and, consequently, changes in the microhardness of these tissues $[7,10,17,19]$. Thus, the objective of this study was to carry out a conformational and constitutional evaluation of teeth with DCIR, comparing them to teeth with conventional caries and to healthy teeth.

\section{Materials and methods}

This study was approved by the Research Ethics Committee of the University (Number 1.618.336).
Twenty-four human permanent teeth were obtained from the Biobank and Biorepository of the School of Dentistry. The selection of teeth was performed visually according to the type of teeth and the presence or absence of caries lesions. Then, the teeth were separated into three groups: 1) Group GDCIR - eight teeth with caries related to ionizing radiation; 2) Group GCC - eight teeth with conventional caries, and 3) Group GHT - eight healthy teeth.

All teeth were evaluated macroscopically to verify the presence or not of caries lesions. The morphological aspects related to the loss of tooth structure in the GDCIR group were determined by two examiners, using the Post-Radiotherapy Caries Index described by Walker et al. [20] and adapted for extracted teeth.

Information regarding radiotherapy was collected from the medical records of patients who donated their teeth with DCIR. Only teeth from patients with cancer in the head and neck region who had been treated by radiotherapy were included in this study (minimum therapeutic dose of $60 \mathrm{~Gy}$ ). The teeth of each group were matched according to their anatomy.

\section{Radiographic evaluation}

The teeth were radiographed using the film Dentus E-Speed, $3 \times 4 \mathrm{~cm}$ (Agfa/Heraeus Kulzer, Belgium), and X-rays equipment Xdent D70 (Xdent Equipamentos Odontológicos, Brazil). The films were positioned $30 \mathrm{~cm}$ from the X-ray emission source. All teeth were supported on them in the buccal-lingual and mesio-distal positions. A total of 48 radiographs were taken. The films were processed in a Revell automatic processor (Del Grandi, Brazil). X-rays were digitized using a scanner for radiographic HP Scanjet G4050 (Hewlett Packard Development Company, USA). Then, all teeth were positioned in a semi-circular shape and stabilized on ethylene-vinyl acetate - EVA foam plates (Eduart, Brazil). This set was taken to the i-Cat Next Generation cone beam computed tomography (Imaging Sciences International, USA). During the reformatting of the images, approximately 530 axial sections were obtained, with a thickness of $0.5 \mathrm{~mm}$. The image evaluation was performed with the help of the iCat Vision program version 1.9.3.14 (CT Dent, England) and the visualization of sections every $1.5 \mathrm{~mm}$ in the coronal, sagittal, and axial 
planes. All radiographic and tomographic images were analyzed randomly by a single examiner who did not know the groups.

\section{Evaluation by computerized microtomography}

The samples were submitted to the SkyScan 1172 $\mathrm{X}$-ray computerized microtomography (SkyScan, Belgium). About 1300 cuts were acquired (only from the coronary portion and the upper root of the teeth) to assess the cervical region. NRecon version 1.6.9.3 (SkyScan, Belgium) was used to reformat the images in tomographic sections. These sections were then processed in the Data Viewer software version 1.5.2.4 (SkyScan, Belgium) and could be viewed on the three axes simultaneously.

\section{Teeth preparation}

Two faces of each tooth were prepared for constitutional, microstructural, and conformational evaluation: a) dentin surface - face exposed to the oral environment in the cervical region and $b$ ) internal face - cut parallel to the long axis of the tooth, in the center of the carious lesion towards the pulp chamber/pulp canal. The teeth were cut, polished, and cleaned.

\section{Chemical analysis}

The evaluation of the chemical elements of the samples was performed using an X-ray dispersive energy spectroscope (EDX, Oxford Instruments, England) coupled to the SEM. This analysis was done on the inner face, in the cut made along the long axis of the tooth. The AZtec 3.1 program (Oxford Instruments, England) was used to analyze the data obtained from spectroscopy. The following chemical elements were selected to measure the relative quantity according to their atomic number: $\mathrm{C}, \mathrm{P}$, and $\mathrm{Ca}$.

\section{Microstructural and conformational analysis}

The samples were subjected to ionic metallization with gold $(\mathrm{Au})$ using an automatic pressure metallizer SCD-030 (Balzers Union, Liechtenstein) after analysis of the chemical composition of the teeth. Each tooth was evaluated using SEM Tescan Vega3 LMU (Tescan, Czech Republic). The superficial region of the cavities was evaluated. The scanning electron microscope allowed two types of analysis: a) microstructural - a qualitative observation with increases of $50 \times, 500 \times, 5,000 \times$, and $25,000 \times$; b) conformational - evaluation of the surface roughness and topography of the dentin surface. The Vega3 Control Software 4.2 program (Tescan, Czech Republic) was used to evaluate the microstructure. For conformational evaluation, the MeX 3D Measurement program (Alicona Imaging $\mathrm{GmbH}$, Austria) was used. The measure used for statistical calculations was 'Sz' (name generated by the program). It calculates the difference between the average peaks of a given area and the average of valleys in a given area, in " $\mu \mathrm{m}$ ".

\section{Statistical analysis}

Statistical analysis was performed using the software Statistical Package for Social Sciences 20.0 (IBM Inc., Chicago, EUA). The homogeneity of the variables was verified using the Levene test. The ANOVA test was used to analyze the correlation between the three groups of teeth. Besides, the Tukey HSD test was used to determine the significant differences between the means of all groups. Values of $\mathrm{p}<0.05$ were considered significant.

\section{Results}

The teeth used in this study and the respective treatment regimens used to treat patients are shown in Table 1. Most patients were adult men who had a tumor treated in the oropharynx region by a combination of radio- and chemotherapy. All patients had been treated by $3 \mathrm{D}$ conformal radiotherapy, ranged from 60 to $70 \mathrm{~Gy}$ total dose (daily fractional dose of $200 \mathrm{cGy}$ during 30 to 35 radiation therapy sessions).

The macroscopic evaluation revealed that all teeth with conventional caries exhibited cavitations (Fig. 1, columns 1 and 2). Also, spots ranging from brown to black were observed on the surface compromised by DCIR.

Periapical radiographs revealed that teeth with DCIR did not have cavitation. However, the compromised regions exhibited radiolucency consistent with loss of mineral structure (Fig. 1, columns 3 and 4). The analysis of sections obtained by cone beam computed tomography revealed radiolucent images suggestive of a greater area of mineral loss. A marked difference between both types of caries was more evident in the images obtained by cone 
Table 1. Teeth and clinical data of patients included in the survey

\begin{tabular}{|c|c|c|c|c|c|c|c|}
\hline Tooth & Sex & Age & $\begin{array}{l}\text { Localization } \\
\text { of the tumor }\end{array}$ & Treatment & $\begin{array}{c}\text { Type } \\
\text { of radiotherapy }\end{array}$ & $\begin{array}{l}\text { Radiotherapy } \\
\text { dose }\end{array}$ & $\begin{array}{c}\text { Number of sessions/ } \\
\text { /fractions* }\end{array}$ \\
\hline Upper molar & Male & 49 & Tongue (base) & RT & $3 D$ & $66 \mathrm{~Gy}$ & 33 \\
\hline Lower molar & Male & 48 & Oropharynx & $\mathrm{RT}+\mathrm{CHT}$ & $3 \mathrm{D}$ & $66 \mathrm{~Gy}$ & 33 \\
\hline $\begin{array}{l}\text { Upper central } \\
\text { incisor }\end{array}$ & Female & 61 & Jaw & $\mathrm{RT}+\mathrm{CHT}$ & $3 \mathrm{D}$ & 70 Gy & 35 \\
\hline $\begin{array}{l}\text { Upper } \\
\text { premolar }\end{array}$ & Male & 62 & Tongue & $\mathrm{RT}+\mathrm{CHT}$ & $3 \mathrm{D}$ & 60 Gy & 30 \\
\hline Lower canine & Male & 63 & $\begin{array}{l}\text { Oropharynx and } \\
\text { tongue }\end{array}$ & $\mathrm{RT}+\mathrm{CHT}$ & $3 D$ & 60 Gy & 33 \\
\hline Lower canine & Female & 53 & Palate & RT + Surgery & $3 \mathrm{D}$ & 70 Gy & 35 \\
\hline $\begin{array}{l}\text { Lower lateral } \\
\text { incisor }\end{array}$ & Male & 53 & Oropharynx & $\mathrm{RT}+\mathrm{CHT}$ & $3 \mathrm{D}$ & 66 Gy & 33 \\
\hline Lower canine & Male & 55 & Oropharynx & $\mathrm{RT}+\mathrm{CHT}$ & $3 D$ & $66 \mathrm{~Gy}$ & 33 \\
\hline
\end{tabular}

RT — radiotherapy; CHT — chemotherapy (cisplatin and fluorouracil); *200cGy per fraction

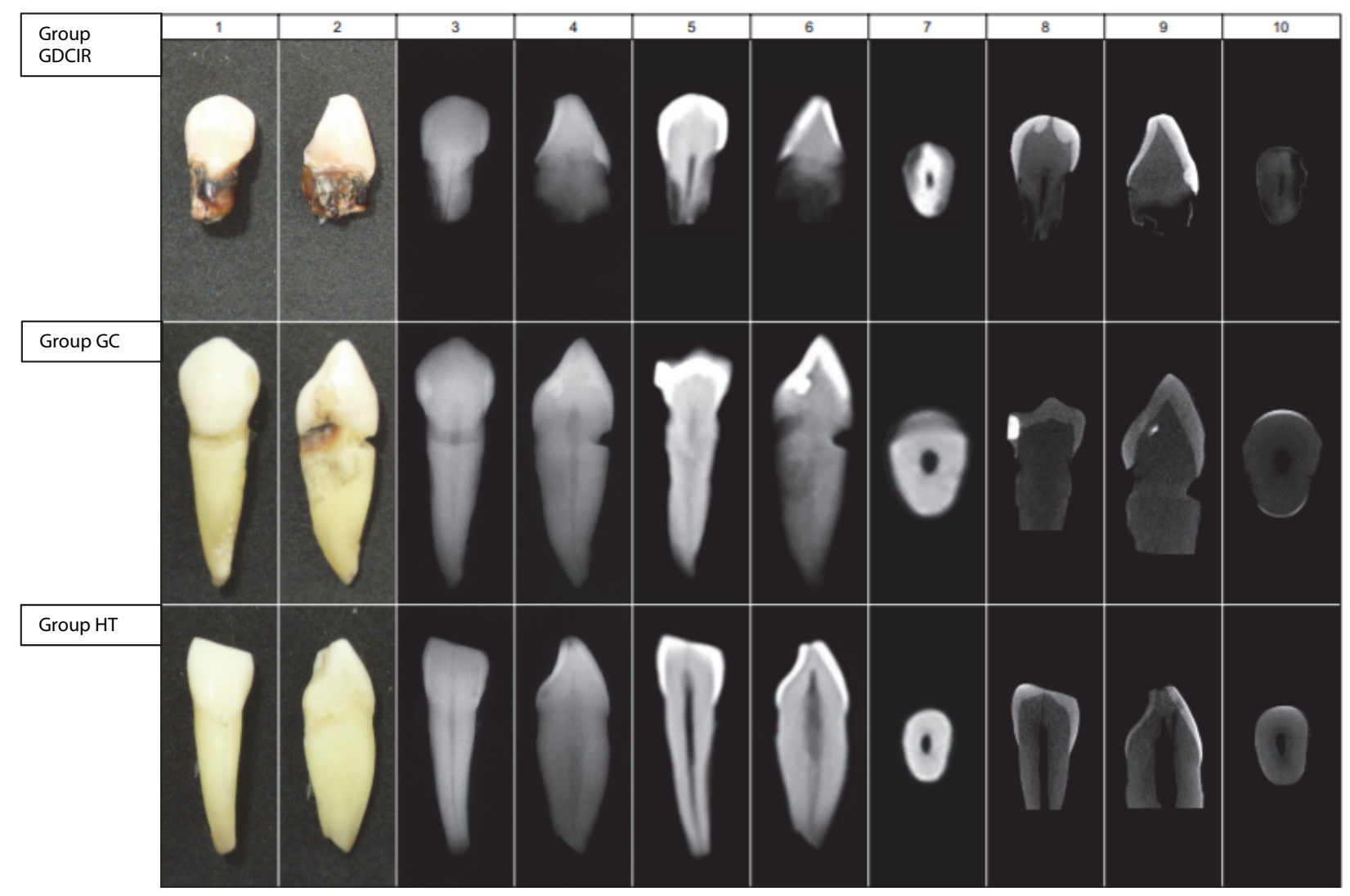

Figure 1. Clinical and imaginological images of teeth with dental caries related to ionizing radiation (DCIR), conventional carie and healthy. Columns 1 and 2: Clinical. Columns 3 and 4: radiographic images. Columns 5 and 6: tomographic images. Columns 7-10: images by micro CT scanning; GDCIR — eight teeth with caries related to ionizing radiation; GCC — eight teeth with conventional caries; GHT — eight healthy teeth

beam computed tomography (Fig. 1, columns 5 and 7).

The analysis of caries lesions made by computerized microtomography showed that there was a dif- ference in DCIR lesions when compared to conventional caries. The DCIR showed an extensive area with a loss of mineralized structure (Fig. 1, columns 8 to 10). These changes were observed 


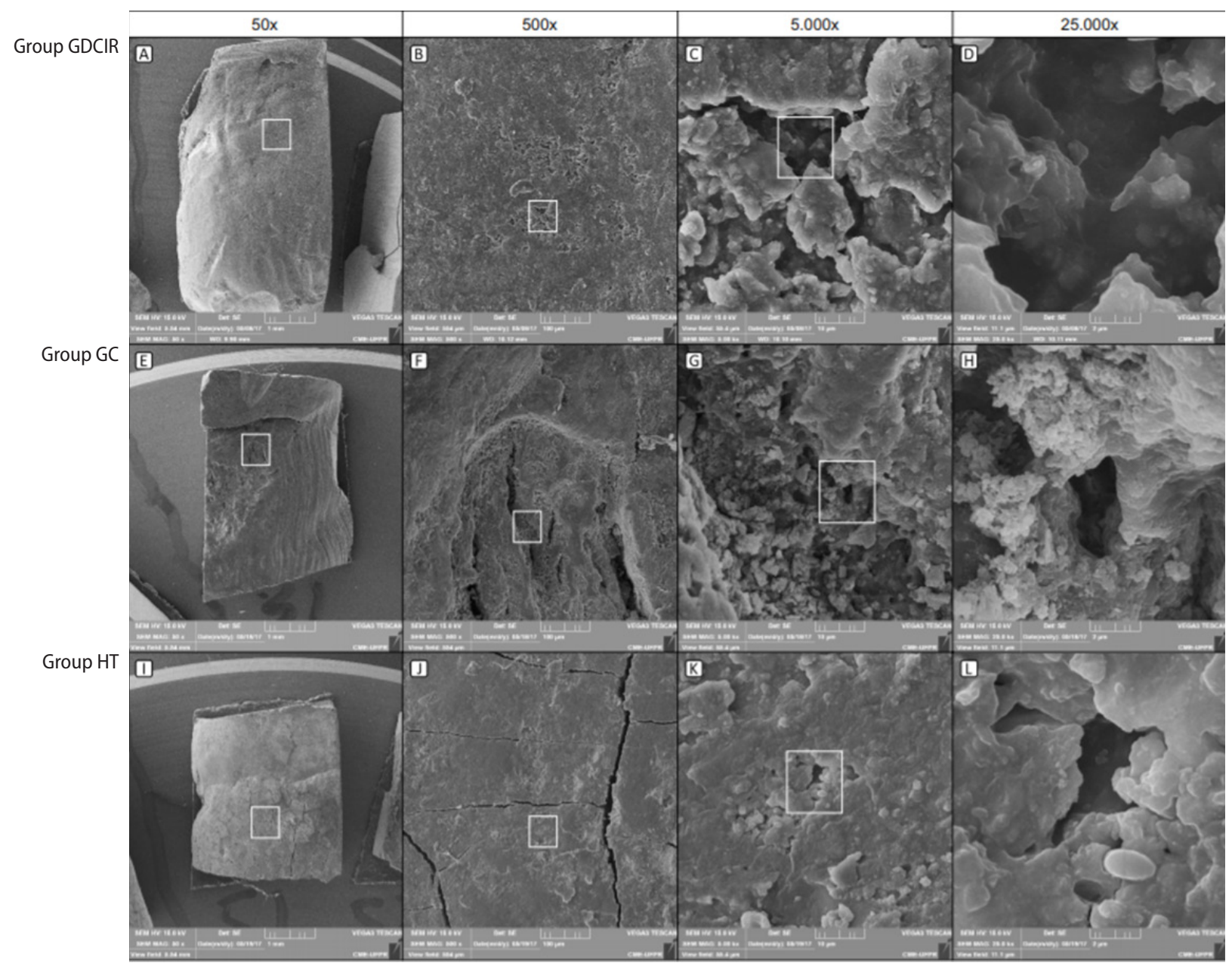

Figure 2. SEM photomicrographs of dental surface. $A, B, C, D$ : Teeth with dental caries related to ionizing radiation (DCIR); E, F, G, H: Teeth with conventional caries; I, J, K, L: Healthy teeth; A, E, I: at 50x magnification; B, F, J: at 500x magnification; C, G, K: at 5,000x magnification; D, H, L: at 25,000x magnification; the rectangles refer to the area selected for the next magnification. GDCIR — eight teeth with caries related to ionizing radiation; GCC — eight teeth with conventional caries; GHT — eight healthy teeth

even in caries regions with a smooth surface and a brownish color (Fig. 1, columns 1 e 2). On the other hand, the mineral loss of teeth with conventional caries was restricted to the cavitation region and with less penetration towards the pulp chamber.

The evaluation of the superficial microstructure of all teeth was performed with four different magnifications using SEM. Magnifications of 50x and 500x have revealed that surfaces with DCIR (Fig. 2A and 2B) and healthy dentin (Fig. 2I and 4J) were more regular. The teeth compromised by conventional caries presented a more irregular surface. The presence of cavitation and cracks in the mineral structure were observed (Fig. 2E and 2F). In the increases of 5,000x and 25,000x, greater mineral disorganization was observed in teeth with DCIR
(Figures 2C and 2D) and a more homogeneous structure in healthy teeth (Fig. $2 \mathrm{~K}$ and $2 \mathrm{~L}$ ).

The superficial topography and roughness were evaluated using the SEM and the MeX software through color scale and numerical scale. The superficial roughness of teeth with DCIR (Fig. 3A) was lower when compared to teeth with conventional caries (Fig. 3B). On the other hand, this roughness was greater when compared to healthy teeth (Fig. 3C).

The values of individual surface roughness and topography for each tooth, the mean and standard deviation for the different groups are shown in Table 2. There was no statistical difference in surface roughness between different types of caries $(p=0.709)$. The superficial roughness of teeth with DCIR and healthy teeth also did not show a sta- 


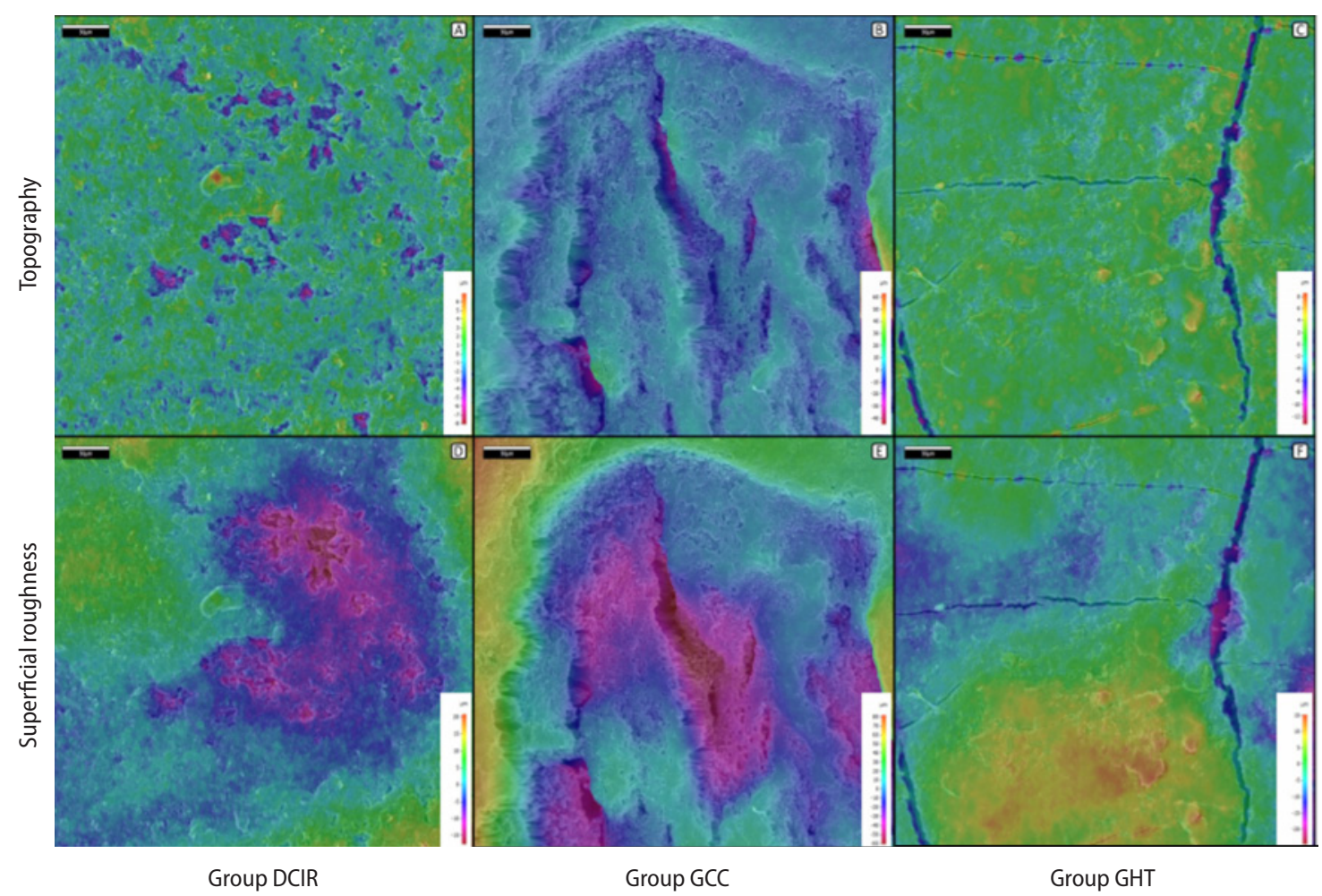

Figure 3. SEM photomicrographs of dental surface. Images in the upper region — topography. Images in the lower region - surface roughness

Table 2. Values of roughness and surface topography of teeth according to groups

\begin{tabular}{|c|c|c|c|c|c|c|c|c|c|c|}
\hline Groups & $\begin{array}{c}\text { Upper } \\
\text { molar } \\
{[\mu \mathrm{m}]}\end{array}$ & $\begin{array}{c}\text { Upper } \\
\text { molar } \\
{[\mu \mathrm{m}]}\end{array}$ & $\begin{array}{l}\text { Upper central } \\
\text { incisor [ } \mu \mathrm{m}]\end{array}$ & $\begin{array}{c}\text { Upper } \\
\text { premolar } \\
{[\mu \mathrm{m}]}\end{array}$ & $\begin{array}{l}\text { Lower } \\
\text { canine } \\
{[\mu \mathrm{m}]}\end{array}$ & $\begin{array}{l}\text { Lower } \\
\text { canine } \\
{[\mu \mathrm{m}]}\end{array}$ & $\begin{array}{l}\text { Lower lateral } \\
\text { incisor }[\mu \mathrm{m}]\end{array}$ & $\begin{array}{l}\text { Lower } \\
\text { canine } \\
{[\mu \mathrm{m}]}\end{array}$ & $\begin{array}{c}\text { Mean } \\
{[\mu \mathrm{m}]}\end{array}$ & SD \\
\hline \multicolumn{11}{|c|}{ Roughness } \\
\hline GDCIR & 27.12 & 38.89 & 109.88 & 23.09 & 279.73 & 15.07 & 227.38 & 73.12 & 47.86 & 36.56 \\
\hline GCC & 67.01 & 66.25 & 36.67 & 62.97 & 90.19 & 108.21 & 15.47 & 28.79 & 59.44 & 31.24 \\
\hline GHT & 16.82 & 10.91 & 8.53 & 15.67 & 26.24 & 21.96 & 13.57 & 15.93 & 16.20 & 5.71 \\
\hline \multicolumn{11}{|c|}{ Topography } \\
\hline GDCIR & 66.59 & 132.90 & 109.90 & 32.65 & 366.69 & 38.43 & 344.46 & 207.15 & 97.93 & 66.45 \\
\hline GCC & 240.85 & 186.17 & 86.94 & 230.74 & 298.94 & 143.12 & 62.92 & 63.81 & 164.19 & 89.19 \\
\hline GHT & 27.86 & 31.09 & 19.20 & 25.01 & 30.94 & 39.75 & 27.69 & 25.11 & 28.33 & 5.98 \\
\hline
\end{tabular}

GDCIR — eight teeth with caries related to ionizing radiation; GCC — eight teeth with conventional caries; GHT — eight healthy teeth

tistical difference $(\mathrm{p}=0.101)$. On the other hand, a statistically significant difference was observed between the superficial roughness of healthy teeth and conventional caries $(\mathrm{p}=0.012)$.

The topography analysis showed that the surfaces of the examined teeth were similar (Fig. 3D-3F). The teeth with DCIR showed an average topographic irregularity (the difference between maximum peak and minimum depth) of $97.93 \mu \mathrm{m}$ $( \pm 66.45 \mu \mathrm{m})$. In teeth with conventional caries and healthy, the mean values for the topography irregularity were $164.19 \mu \mathrm{m}( \pm 89.19 \mu \mathrm{m})$ and $28.33 \mu \mathrm{m}$ $( \pm 5.98 \mu \mathrm{m})$, respectively. Table 3 presents the values of the topography observed in each tooth individually. There was no statistical difference in topography between DCIR and conventional caries $(p=0.162)$. Likewise, there was no statistical difference between teeth with DCIR and healthy teeth $(\mathrm{p}=0.137)$. There was a statistically significant difference between teeth with conventional 
Table 3. Crossing between groups for the variables roughness and surface topography

\begin{tabular}{|c|c|c|c|c|}
\hline Crossings & $\begin{array}{l}\text { Mean difference module } \\
{[\mu \mathrm{m}]}\end{array}$ & Standard error $[\mu \mathrm{m}]$ & p-value & $\begin{array}{l}\text { Confidence interval 95\% } \\
\text { Lower limit/Upper limit }\end{array}$ \\
\hline \multicolumn{5}{|l|}{ Roughness } \\
\hline GDCIR $\times$ GCC & 11.58 & 15.52 & 0.709 & $-48.48 / 25.32$ \\
\hline GDCIR x GHT & 31.66 & 14.52 & 0.101 & $-5.24 / 68.56$ \\
\hline GCC $x$ GHT & 43.24 & 13.45 & $0.012^{*}$ & $9.08 / 77.40$ \\
\hline \multicolumn{5}{|l|}{ Topography } \\
\hline GDCIR $\times$ GCC & 66.25 & 34.61 & 0.162 & $154.17 / 21.67$ \\
\hline GDCIR $x$ GHT & 69.60 & 34.61 & 0.137 & $18.32 / 157.52$ \\
\hline GCC x GHT & 135.85 & 32.04 & $0.001 *$ & 217.25 \\
\hline
\end{tabular}

GDCIR - eight teeth with caries related to ionizing radiation; GCC — eight teeth with conventional caries; GHT — eight healthy teeth

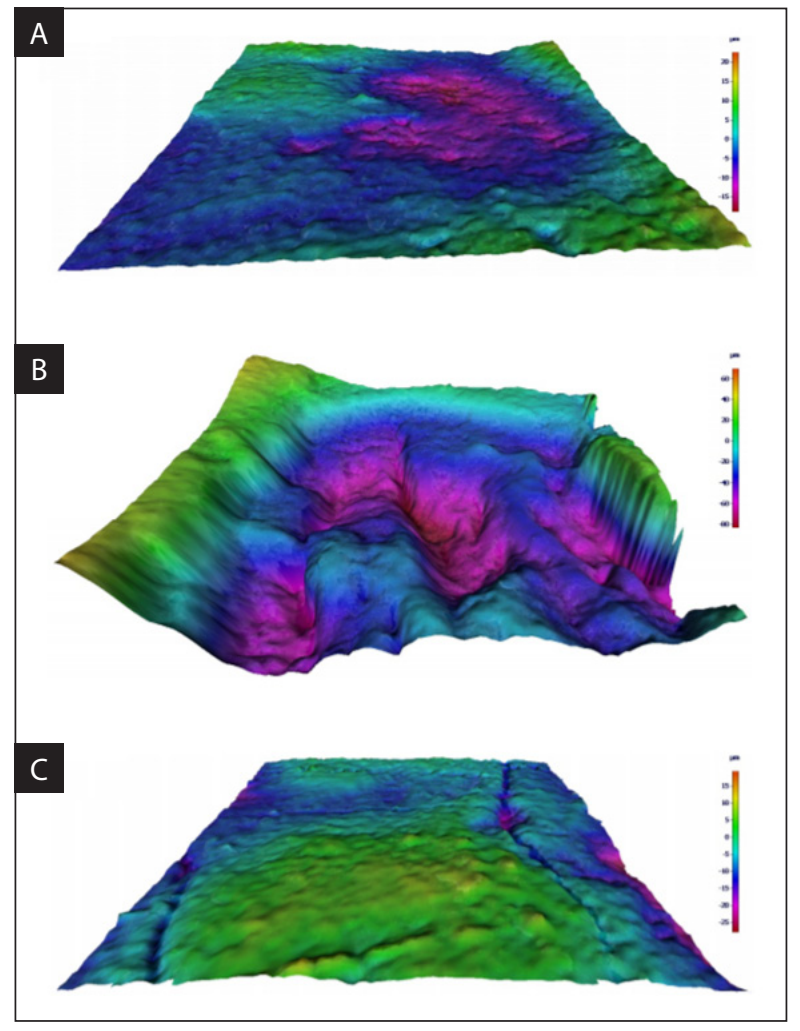

Figure 4. Three-dimensional projection of superficial topography by SEM. A. Tooth with caries related to ionizing radiation. B. Tooth with conventional caries. C. Healthy tooth

caries and healthy teeth $(\mathrm{p}=0.001)$. Figure 4 shows the patterns of the three-dimensional projection of the surface topography of the analyzed teeth.

The quantitative analysis of the chemical constitution of each tooth in the different groups and their relations are shown in Table 3. Spectroscopy revealed that there were statistically significant differences in $\mathrm{Ca}$ and $\mathrm{P}$ levels between the three groups. Also, an increase in C levels was observed.
The mean Ca was lower in DCIR (13.72 \pm 4.22 $\mu \mathrm{m})$ when compared to teeth with conventional caries $(18.77 \pm 2.47)$ and healthy teeth $(22.87 \pm 1.38$ $\mu \mathrm{m})$, with $\mathrm{p}<0.05$. The mean $\mathrm{P}$ was lower in DCIR $(6.77 \pm 2.02 \mu \mathrm{m})$ when compared to teeth with conventional caries $(9.47 \pm 1.43)$ and healthy teeth $(11.72 \pm 0.47 \mu \mathrm{m})$. On the other hand, the average of $\mathrm{C}$ atoms was higher in teeth with DCIR $(42.37 \pm 7.80 \mu \mathrm{m})$, lower in those with conventional caries $(32.99 \pm 4.38 \mu \mathrm{m})$ and also in healthy teeth $(25,28 \pm 1.84 \mu \mathrm{m})$. The relationships between chemical elements also varied between groups. When the $\mathrm{Ca} / \mathrm{P}$ rates between the DCIR $(2.02 \pm 0.04)$ and healthy teeth $(1.95 \pm 0.05)$ were compared, a statistically significant reduction $(p=0.016)$ was observed. The comparison between groups of teeth with conventional caries and healthy teeth showed no statistical difference $(\mathrm{p}=0.300)$.

\section{Discussion}

Oral cancer is an emerging disease in several countries and is considered a public health problem [21]. The treatment of this disease may involve different therapeutic modalities: surgical, chemotherapy, and radiotherapy [22]. Many patients, when submitted to radiotherapy in the head and neck, may develop DCIR lesions. According to de Pauli Paglioni et al. [23], DCIR is associated with elevated DMFT (decayed, missing, and filled teeth) index. This demonstrates that the patient undergoing radiotherapy has poor oral health and low quality of life. However, the pathophysiology of DCIR is not yet fully understood. Thus, this study aimed to investigate the lesions of DCIR, morphologically and chemically. 
Table 4. Absolute percentage of atomic mass (Wt\%) for the elements calcium, phosphorus and carbon according to groups

\begin{tabular}{|c|c|c|c|}
\hline Chemical elements & $\begin{array}{l}\text { Caries related to ionizing } \\
\text { radiation } \mathrm{Wt} \% \pm \mathrm{SD}\end{array}$ & $\begin{array}{c}\text { Conventional caries } \\
\text { Wt } \% \pm \text { SD }\end{array}$ & $\begin{array}{l}\text { Healthy teeth } \\
\mathrm{Wt} \% \pm \mathrm{SD}\end{array}$ \\
\hline Calcium & $13,72 \pm 4.22$ & $18.77 \pm 2.47$ & $22.87 \pm 1.38$ \\
\hline Phosphorus & $6.77 \pm 2.02$ & $9.47 \pm 1.43$ & $11.72 \pm 0.47$ \\
\hline Carbon & $42.37 \pm 7.80$ & $32.99 \pm 4.38$ & $25.28 \pm 1.84$ \\
\hline Calcium/Phosphorus & $0.35 \pm 0.17$ & $0.59 \pm 0.14$ & $0.91 \pm 0.12$ \\
\hline Calcium/Carbon & $2.02 \pm 0.04$ & $1.99 \pm 0.06$ & \pm 0.05 \\
\hline
\end{tabular}

SD — standard deviation

Table 5. Crossing of groups of teeth in relation to chemical elements and their relationships

\begin{tabular}{|c|c|c|c|c|c|}
\hline Crossings & Calcium (Wt\%) & Phosphorus (Wt\%) & Carbon (Wt\%) & Calcium/Phosphorus & Calcium/Carbon \\
\hline \multicolumn{6}{|l|}{ DM (p-value) } \\
\hline GDCIR x GCC & $5.05(0.007)^{*}$ & $9.39(0.005)^{*}$ & $-2.71(0.004)^{*}$ & $0.04(0.300)$ & $0.24(0.010)^{*}$ \\
\hline GDCIR x GHT & $9.15(0.000)^{*}$ & $17.09(0.000)^{*}$ & $-4.95(0.000)^{*}$ & $0.08(0.016)^{*}$ & $0.56(0.000)^{*}$ \\
\hline GCC $x$ GHT & $4.10(0.028)^{*}$ & $7.71(0.021)^{*}$ & $2.25(0.015)^{*}$ & $0.04(0.300)$ & $0.33(0.001)^{*}$ \\
\hline
\end{tabular}

GDCIR — eight teeth with caries related to ionizing radiation; GCC — eight teeth with conventional caries; GHT — eight healthy teeth; DM — mean difference module; $\mathrm{Wt} \%$ - absolute percentage of atomic mass; * statistical difference

The teeth with DCIR presented the brownish aspect on two or more faces as observed by other authors $[10,11,14]$. In most cases, this color change can confuse the dental surgeon who may underestimate the lack of cavitation and not give due importance to the establishment of a fast and adequate treatment $[13,14]$. On the other hand, teeth with conventional caries showed small cavitation and restricted to the cervical region.

When these types of caries are studied using the imaging resources available, the clinical aspect without cavitation of DCIR and a "possibility" of no demineralization may suggest other hypotheses. Periapical radiographs are capable of showing radiolucent images where there has not yet been a considerable mineral loss, as described by Silva et al. [14] In our study, it was possible to observe this situation through the periapical radiographs that were also confirmed with the computed tomography.

The sensitivity of cone beam computed tomography revealed the highest degree of demineralization of DCIR when compared to conventional caries. These results corroborate the findings of other studies $[7,10,11]$. The analyses made by microtomography suggest that, despite the clinical appearance without cavitation, there is a high degree of demineralization in DCIR [11]. On the other hand, in the case of conventional caries, demineralization occurs around the lesion. These same findings were observed by Morais-Faria et al. [11]. These authors also evaluated teeth with DCIR and conventional caries using computerized microtomography. Imaging resources used allowed the visualization of the teeth in three dimensions (sagittal, coronal, or axial). In this way, the X-ray was able to pass through the teeth without resistance, especially in DCIR lesions due to low mineralization. These findings reinforce the existence of regions apparently without mineral structure. Previous studies had already reported such changes in both DCIR and conventional caries $[8,14,17,19]$.

Dental caries is a disease that causes profound changes in the mineral structure of the teeth and that can determine the increase in tooth fragility [7, 10, 17, 19]. Kielbassa et al. [7] developed a study with polarized light microscopy and showed that the surface of DCIR is similar to that of healthy dentin in the cervical region. With the use of SEM and specific software to assess surface topography, we observed a similar result.

When teeth with DCIR were compared to healthy teeth, they surprisingly showed no significant changes in surface irregularity (in terms of either roughness or topography). On the other hand, there was a significant difference when compared to conventional caries, which presented greater topographic irregularity. The results of this analysis of the surface corroborated the findings of the macroscopic evaluation. These findings suggest the false 
impression that there is no loss of mineral structure $[10,11]$.

Spectroscopy was used to identify the different chemical elements present in mineral structures $[15,16]$. In our study, the analysis of the chemical composition reinforced the findings observed in periapical radiographs, CT scans, and microtomography. The $\mathrm{Ca} / \mathrm{P}$ ratio reflected the mineral composition of the crystalline structure of the teeth. Significant chemical changes could be observed when teeth with DCIR were compared to healthy teeth. Similar changes had previously been identified by other authors who revealed a loss of minerals in dentine with conventional caries versus healthy dentin [15].

Our study showed that there was a significant decrease in the amount of $\mathrm{Ca}$ and $\mathrm{P}$ in teeth with conventional caries when compared to healthy teeth. However, the greatest reduction was seen in teeth with DCIR. An inverse relationship can be observed with the amount of carbon in the different groups. Dispersive X-ray spectroscopy revealed that there was a greater amount of carbon in the DCIR areas when compared to conventional caries and the healthy dentin surface. The reduced amount of $\mathrm{Ca}$ and $\mathrm{P}$ suggests that the mineral matrix of the teeth with DCIR was altered and reinforce even more the findings of the imaging exams.

Additionally, microCT revealed that there were large areas of hypodensity in the DCIR samples. Also, these results allow us to believe that there is little or no mineral matrix in that region. This result corroborates the results observed by EDX. However, the literature reports that DCIR and conventional caries have the same demineralization patterns [14].

Our study was able to demonstrate that there is a difference between both types of caries according to different types of analyses (radiographs, tomography, microtomography, chemical composition, surface roughness, and topography). Macro- and microscopic evaluations showed similarities between the surfaces of DCIR and healthy teeth and significant differences when compared to conventional caries. The analysis of the images and the chemical composition showed the opposite, as the DCIRs determine a profound pattern of demineralization of the dental structure and loss of chemical elements. On the other hand, in conventional caries lesions, they present a lower, but also significant, degree of demineralization. The lesions of DCIR can clinically look like aggressive and destructive injuries. The apparent superficial smoothness and the lack of cavitation disguise an extensive loss of mineral matrix that occurs in the tooth structure, as seen in the images and in the values of $\mathrm{Ca}$ and $\mathrm{P}$ losses, for reasons not yet fully elucidated.

The small sample size was the main limitation of our study. This was due to the difficulty of getting teeth with DCIR less destroyed. Obtaining teeth with this disease is not an easy job. When DCIR is not treated, it can progress quickly and require restorative treatment or surgical removal of the tooth. Dental extraction in patients who were treated by high-dose radiotherapy in the region represents a risk for osteoradionecrosis, especially in the mandible. So, when an extraction needs to be performed on an irradiated patient, it needs to be very well planned [20]. Besides, the evolution of DCIR lesions is rapid and can lead to early tooth loss due to fracture of the crown. The teeth with DCIR used in this study still had their anatomical crown well preserved. They had been surgically removed because of advanced periodontal disease or had undergone coronectomy after endodontic treatment. Also, it was not possible to determine the degree of hyposalivation and xerostomia in patients who had DCIR. However, all patients had poor oral health because they had not adhered to oral hygiene care determined by the hospital's dental surgeon.

The literature also reinforces the need to pair the samples with the type of tooth, the region to be investigated, and the patient's age [24-26]. The teeth used in this study were matched according to the anatomy of the teeth and their cervical region. On the other hand, it was not possible to standardize the age of patients who donated their teeth to the control groups (conventional caries and healthy teeth), because priority was given to the similarity of caries lesions from a macroscopic point of view.

Finally, the lesions of DCIR macroscopically presented with a brownish, smooth, and intact surface. However, imaging studies revealed that these areas had a radiolucency pattern compatible with a greater loss of mineral structure when compared to conventional caries. The chemical composition of the DCIR lesions was significantly altered with a decrease in $\mathrm{Ca}$ and $\mathrm{P}$ and an increase in C. From the microscopic point of view, the DCIR lesions showed a superficial irregularity similar to a healthy 
tooth and less when compared to conventional caries.

Also, it is important to note that DCIR is a multifactorial disease and that the clinician must also be aware of changes in patient's microbiota, diet, and saliva. All of these factors associated with changes in tooth structure contribute to the development and rapid progression of lesions. Thus, the clinician needs to know and diagnose DCIR to adopt effective therapeutic measures as soon as possible. These measures include better adequacy of the oral environment, with hygiene and proper maintenance and restorative procedures, when necessary.

\section{Conclusion}

Despite their rapid evolution, DCIR lesions present an irregular, apparently intact surface with significant changes in the amount of $\mathrm{Ca}, \mathrm{P}$, and $\mathrm{C}$.

\section{Conflict of interests}

None declared.

\section{Funding}

None declared.

\section{Acknowledgment}

The authors would like to thank the Center for Electron Microscopy and the LAMIR Institute - Institute of the Laboratory for Analysis of Minerals and Rocks at UFPR.

\section{References}

1. Semrau R. The Role of Radiotherapy in the Definitive and Postoperative Treatment of Advanced Head and Neck Cancer. Oncol Res Treat. 2017; 40(6): 347-352, doi: 10.1159/000477128, indexed in Pubmed: 28521321.

2. Koh J, Walsh P, D'Costa I, et al. Head and neck squamous cell carcinoma survivorship care. Aust J Gen Pract. 2019; 48(12): 846-848, doi: 10.31128/AJGP-08-19-5032, indexed in Pubmed: 31774982.

3. Cho H, Kumar N. Dental management of a patient with head and neck cancer: a case report. Br Dent J. 2019; 227(1): 25-29, doi: 10.1038/s41415-019-0464-7, indexed in Pubmed: 31300776.

4. Strojan P, Hutcheson KA, Eisbruch A, et al. Treatment of late sequelae after radiotherapy for head and neck cancer. Cancer Treat Rev. 2017; 59: 79-92, doi: 10.1016/j. ctrv.2017.07.003, indexed in Pubmed: 28759822.

5. Lalla RV, Treister N, Sollecito T, et al. OraRad Study Group. Oral complications at 6 months after radiation therapy for head and neck cancer. Oral Dis. 2017; 23(8): 1134-1143, doi: 10.1111/odi.12710, indexed in Pubmed: 28675770.
6. Høxbroe Michaelsen S, Grønhøj C, Høxbroe Michaelsen $J$, et al. Quality of life in survivors of oropharyngeal cancer: A systematic review and meta-analysis of 1366 patients. Eur J Cancer. 2017; 78: 91-102, doi: 10.1016/j. ejca.2017.03.006, indexed in Pubmed: 28431302.

7. Kielbassa AM, Schendera A, Schulte-Mönting J. Microradiographic and microscopic studies on in situ induced initial caries in irradiated and nonirradiated dental enamel. Caries Res. 2000; 34(1): 41-47, doi: 10.1159/000016568, indexed in Pubmed: 10601783.

8. Kielbassa A, Hinkelbein W, Hellwig E, et al. Radiationrelated damage to dentition. Lancet Oncol. 2006; 7(4): 326-335, doi: 10.1016/s1470-2045(06)70658-1, indexed in Pubmed: 16574548.

9. Moore C, McLister C, Cardwell C, et al. Dental caries following radiotherapy for head and neck cancer: A systematic review. Oral Oncol. 2020; 100: 104484, doi: 10.1016/j.oraloncology.2019.104484, indexed in Pubmed: 31786391.

10. de Oliveira Mota CC, Gueiros LA, Maia AM, et al. Optical coherence tomography as an auxiliary tool for the screening of radiation-related caries. Photomed Laser Surg. 2013; 31(7): 301-306, doi: 10.1089/pho.2012.3415, indexed in Pubmed: 23819504.

11. Morais-Faria K, Neves-Silva R, Lopes MA, et al. The wolf in sheep's clothing: Microtomographic aspects of clinically incipient radiation-related caries. Med Oral Patol Oral Cir Bucal. 2016; 21(3): e299-e304, doi: 10.4317/ medoral.20886, indexed in Pubmed: 26946198.

12. Springer IN, Niehoff $P$, Warnke $P H$, et al. Radiation caries--radiogenic destruction of dental collagen. Oral Oncol. 2005; 41(7): 723-728, doi: 10.1016/j.oraloncology.2005.03.011, indexed in Pubmed: 15979926.

13. Lieshout HFJ, Bots CP. The effect of radiotherapy on dental hard tissue--a systematic review. Clin Oral Investig. 2014; 18(1): 17-24, doi: 10.1007/s00784-013-1034-z, indexed in Pubmed: 23873320.

14. Silva ARS, Alves FA, Antunes A, et al. Patterns of demineralization and dentin reactions in radiation-related caries. Caries Res. 2009; 43(1): 43-49, doi: 10.1159/000192799, indexed in Pubmed: 19151554.

15. Arnold WH, Konopka S, Kriwalsky MS, et al. Morphological analysis and chemical content of natural dentin carious lesion zones. Ann Anat. 2003; 185(5): 419-424, doi: 10.1016/ S0940-9602(03)80099-7, indexed in Pubmed: 14575268.

16. Arnold WH, Bietau V, Renner PO, et al. Micromorphological and micronanalytical characterization of stagnating and progressing root caries lesions. Arch Oral Biol. 2007; 52(6): 591-597, doi: 10.1016/j.archoralbio.2006.11.008, indexed in Pubmed: 17181998.

17. Deng J, Jackson L, Epstein JB, et al. Dental demineralization and caries in patients with head and neck cancer. Oral Oncol. 2015; 51(9): 824-831, doi: 10.1016/j.oraloncology.2015.06.009, indexed in Pubmed: 26198979.

18. Gomes-Silva W, Prado-Ribeiro AC, Brandão TB, et al. Postradiation Matrix Metalloproteinase-20 Expression and Its Impact on Dental Micromorphology and Radiation-Related Caries. Caries Res. 2017; 51(3): 216-224, doi: 10.1159/000457806, indexed in Pubmed: 28359051.

19. Hong CHL, Napeñas JJ, Hodgson BD, et al. Dental Disease Section, Oral Care Study Group, Multi-national Association of Supportive Care in Cancer (MASCC)/International Society of Oral Oncology (ISOO). A systematic review of dental 
disease in patients undergoing cancer therapy. Support Care Cancer. 2010; 18(8): 1007-1021, doi: 10.1007/s00520010-0873-2, indexed in Pubmed: 20449756.

20. Sroussi HY, Epstein JB, Bensadoun RJ, et al. Common oral complications of head and neck cancer radiation therapy: mucositis, infections, saliva change, fibrosis, sensory dysfunctions, dental caries, periodontal disease, and osteoradionecrosis. Cancer Med. 2017; 6(12): 2918-2931, doi: 10.1002/cam4.1221, indexed in Pubmed: 29071801.

21. Mathew A, Sara George P, M C K, et al. Cancer Incidence and Mortality: District Cancer Registry, Trivandrum, South India. Asian Pac J Cancer Prev. 2017; 18(6): 14851491, doi: 10.22034/APJCP.2017.18.6.1485, indexed in Pubmed: 28669156.

22. Dyzmann-Sroka A, Malicki J. Cancer incidence and mortality in the Greater Poland Region-Analysis of the year 2010 and future trends. Rep Pract Oncol Radiother. 2014; 19(5): 296-300, doi: 10.1016/j.rpor.2014.04.001, indexed in Pubmed: 25184053.
23. de Pauli Paglioni M, Palmier NR, Prado-Ribeiro AC, et al. The impact of radiation caries in the quality of life of head and neck cancer patients. Support Care Cancer. 2020; 28(6): 2977-2984, doi: 10.1007/s00520-019-05171-8, indexed in Pubmed: 31773272.

24. Hobson RS, McCabe JF, Hogg SD. Bond strength to surface enamel for different tooth types. Dent Mater. 2001; 17(2): 184-189, doi: 10.1016/s0109-5641(00)00068-3, indexed in Pubmed: 11163390.

25. Park S, Wang DH, Zhang D, et al. Mechanical properties of human enamel as a function of age and location in the tooth. J Mater Sci Mater Med. 2008; 19(6): 2317-2324, doi: 10.1007/s10856-007-3340-y, indexed in Pubmed: 18157510.

26. Reed R, Xu C, Liu Y, et al. Radiotherapy effect on nanomechanical properties and chemical composition of enamel and dentine. Arch Oral Biol. 2015; 60(5):690-697, doi: 10.1016/j.archoralbio.2015.02.020, indexed in Pubmed: 25766468. 